\title{
Coping with cold: The genome of the versatile marine Antarctica bacterium Pseudoalteromonas haloplanktis TAC125
}

\author{
Claudine Médigue, ${ }^{1}$ Evelyne Krin, ${ }^{2}$ Géraldine Pascal, ${ }^{1,2}$ Valérie Barbe, ${ }^{1}$
} Andreas Bernsel, ${ }^{3}$ Philippe N. Bertin, ${ }^{4}$ Frankie Cheung, ${ }^{5}$ Stéphane Cruveiller, ${ }^{1}$ Salvino D'Amico, ${ }^{6}$ Angela Duilio, ${ }^{7}$ Gang Fang, ${ }^{2}$ Georges Feller, ${ }^{6}$ Christine Ho, ${ }^{5}$ Sophie Mangenot, ${ }^{1}$ Gennaro Marino, ${ }^{7}$ Johan Nilsson, ${ }^{3}$ Ermenegilda Parrilli, ${ }^{7}$ Eduardo P.C. Rocha, ${ }^{2}$ Zoé Rouy, ${ }^{1}$ Agnieszka Sekowska, ${ }^{2,8}$ Maria Luisa Tutino, ${ }^{7}$ David Vallenet, ${ }^{1}$ Gunnar von Heijne, ${ }^{3}$ and Antoine Danchin ${ }^{2,9}$

${ }^{1}$ Genoscope, CNRS-UMR 8030, Atelier de Génomique Comparative, 91006 Evry Cedex, France; ${ }^{2}$ Genetics of Bacterial Genomes, Institut Pasteur, 75724 Paris Cedex 15, France; ${ }^{3}$ Department of Biochemistry and Biophysics, Stockholm University, S-106 91 Stockholm, Sweden; ${ }^{4}$ Dynamique, Evolution et Expression de Génomes de Micro-organismes, Université Louis Pasteur, 67000 Strasbourg, France; ${ }^{5}$ Computer Centre, The University of Hong Kong, Pokfulam, SAR Hong Kong; ${ }^{6}$ Laboratoire de Biochimie, Institut de Chimie B6, Université de Liège, B-4000 Liège-Sart Tilman, Belgium; ' Dipartimento di Chimica Organica e Biochimica, edificio MB, via Cinthia, Complesso Universitario Monte S. Angelo, 80126 Napoli, Italy; ${ }^{8}$ CEA Saclay, Laboratoire Stress Oxydants et Cancer, DSV/DBJC/SBMS, 91191 Gif sur Yvette Cedex, France

\begin{abstract}
A considerable fraction of life develops in the sea at temperatures lower than $15^{\circ} \mathrm{C}$. Little is known about the adaptive features selected under those conditions. We present the analysis of the genome sequence of the fast growing Antarctica bacterium Pseudoalteromonas haloplanktis TAC125. We find that it copes with the increased solubility of oxygen at low temperature by multiplying dioxygen scavenging while deleting whole pathways producing reactive oxygen species. Dioxygen-consuming lipid desaturases achieve both protection against oxygen and synthesis of lipids making the membrane fluid. A remarkable strategy for avoidance of reactive oxygen species generation is developed by $P$. haloplanktis, with elimination of the ubiquitous molybdopterin-dependent metabolism. The P. haloplanktis proteome reveals a concerted amino acid usage bias specific to psychrophiles, consistently appearing apt to accommodate asparagine, a residue prone to make proteins age. Adding to its originality, $P$. haloplanktis further differs from its marine counterparts with recruitment of a plasmid origin of replication for its second chromosome.
\end{abstract}

[Supplemental material is available online at www.genome.org. The sequence data from this study have been submitted to EMBL under accession nos. CR954246 and CR954247. The data are also available at the following Web sites: www.genoscope.cns.fr/agc/mage/ psychroscope and http:/ / bioinfo.hku.hk/PsychroList/.]

Three quarters of the Earth is covered by sea and $>90 \%$ of its surface experiences yearly temperatures $<15^{\circ} \mathrm{C}$, asking for a remarkable adaptation of life to cold conditions. Several marine bacteria have been studied, but so far we possess only limited information about life in the sea at medium and low temperatures (Bartlett 1999; Raven et al. 2002; Thomas and Dieckmann 2002). Furthermore, heterotrophic bacteria in sea ice play a key role in carbon cycling, while little is known about their metabolic features, which are beginning to be deciphered (Moran et al. 2004). Challenges posed by cold to life stem from the slow pace of chemical reactions (for reviews, see Lonhienne et al. 2000; Feller and Gerday 2003; Weber and Marahiel 2003; Georlette et al. 2004), from the constraints induced by the stability of hydrogen bonds (the situation is particularly challenging for folded nucleic acids, i.e., RNA), and from increased solubility of gasses

${ }^{9}$ Corresponding author.

E-mail adanchin@pasteur.fr; fax 331-45-68-89-48.

Article and publication are at http://www.genome.org/cgi/doi/10.1101/ gr.4126905. Article published online before print in September 2005. and stability of radicals. Phylogenetic studies based on 16S rRNA sequences indicated close relationships between marine bacteria within two bacterial divisions, Proteobacteria (in the genera Alteromonas, Colwellia, Glaciecola, Octadecabacter, Pseudoaltermonas, Shewanella, and Vibrio) and Cytophaga-FlexibacterBacteroides (Cytophaga, Flavobacterium, Gelidibacter, and Polaribacter) (Ivanova et al. 2004). Pseudoalteromonas haloplanktis TAC125 has been isolated from an Antarctic coastal sea water sample collected in the vicinity of the French Antarctic station Dumont d'Urville, Terre Adélie (66 $40^{\prime} S ; 140^{\circ} 01^{\prime}$ E). By using genome sequencing, corroborated by in silico and in vivo analyses, we have uncovered exceptional genomic and metabolic features of this $\gamma$-proteobacterium compared with other bacteria from aqueous environments (Supplemental Table 1). These features, some of which explored by physiological experiments, account for their remarkable versatility and fast growth, showing adaptation to rare but periodic situations of abundance, making it an organism of choice for exploring heterologous protein production at low temperature (Tutino et al. 2001; Duilio et al. 
Table 1. General features of the Pseudoalteromonas haloplanktis genome

\begin{tabular}{lcc}
\hline & Chromosome 1 & Chromosome 2 \\
\hline Size (bp) & $3,214,944$ & 635,328 \\
G+C percentage & 41.0 & 39.3 \\
Number of predicted CDSs & 2942 & 546 \\
Average size of CDSs (bp) & 950 & 1013 \\
Percentage coding & 88.6 & 87.3 \\
Number of rRNA operons & & \\
$\quad$ (16S-23S-5S) & 9 & 0 \\
5S rRNA (extra copies) & 1 & 0 \\
Number of tRNAs & 106 & 0 \\
CDSs similar to known proteins & 1123 & 157 \\
Putative functions (limited & & \\
$\quad$ homology/structural features) & 759 & 251 \\
Conserved hypothetical proteins & 694 & 75 \\
Orphan proteins & 325 & 61 \\
Doubtful CDS and gene remnant & 41 & 2 \\
\hline
\end{tabular}

2004). Although cold conditions are so prevalent on Earth, we do not possess at the moment a reference set of annotations for the genome of bacteria thriving in such conditions. The present genome sequence was therefore carefully annotated manually, and annotation will be, as much as possible, continuously refined. We endeavored to post to the community reference databases, allowing investigators to rapidly and efficiently retrieve relevant information while comparing it to what is known in other genomes. In the MaGe platform (www.genoscope.cns.fr/agc/mage/ psychroscope) investigators can not only see gene annotations in parallel with syntenies with the genomes they chose as relevant but compare the annotations with cognate data from the UniProt knowledgebase, as well as explore possible EC numbers, metabolic pathways reconstruction, clusters of orthologous genes, or membrane prediction properties. As a complement, a specialized database, PsychroList (http://bioinfo.hku.hk/PsychroList/), within the GenoChore suite (Fang et al. 2005), allows the user to search for patterns in DNA or protein sequences, taking into account a clustering of genes into formal operons as well as providing extra facilities to query sequences using predefined sequence patterns.

\section{Results and Discussion}

\section{Genome organization}

As in many marine $\gamma$-proteobacteria, the $P$. haloplanktis TAC125 genome is made of two chromosomes (Table 1; Supplemental Table 2). The replication origin of chromosome (chr) I maps near dnaA (McLean et al. 1998; Lobry and Louarn 2003) in a region that is highly conserved in $\gamma$-proteobacteria (Fig. 1). However, in remarkable contrast with the genomes of the vibrios (Okada et al. 2005), the second chromosome does not display a standard GC skew (Supplemental Fig. 1). The pattern observed is likely to be caused by unidirectional replication. To our knowledge, this is the first time that such a system would be uncovered in an authentic bacterial chromosome. This is supported by the signature of R1 plasmid replication (del Solar et al. 1998): the tus and repAlike genes, the repA and $d n a A$ boxes, and the parA and parB genes (Fig. 1). In addition, $k i s B$ and $k i d B$ coding for a typical plasmid maintenance system have also been found in chrII. We chose the start at the centre of a TATATA palindrome near the genes coding for the partition system. The $\mathrm{G}+\mathrm{C}$ content and gene density of chrII match that of chrI (Supplemental Table 2). It contains the essential genes hisS and $g c p E$, in addition to a series of genes ubiquitous in $\gamma$-proteobacteria (Supplemental Table 3). A third of chrII genes have orthologs in Escherichia coli. Remarkably, the whole metabolism of histidine is coded in chrII, in a highly conserved gene cluster (Fig. 1). Nineteen percent of the P. haloplanktis chrII genes show high similarities with plasmid-encoded genes, further suggesting that this replicon was a plasmid recruited to become a chromosome encoding essential genes (Fig. 1; Supplemental Table 2).

Genes around the origin of replication in chromosome display a high level of synteny with genes of other known proteobacteria. chrI codes for nine rDNA clusters (23S, 5S, and $16 \mathrm{~S}$ RNAs, one operon has two copies of the 5S RNA gene), a large number compared with that found in most sequenced $\gamma$-proteobacteria (Ussery et al. 2004). The genome sequence of $P$. haloplanktis TAC125 shows some variability in the rRNA genes of $\sim 1 \%$ (interestingly, most variations correspond to compensating mutations in regions coding for double stranded RNA) (data not shown). However, this probably does not influence phylogenies (Cilia et al. 1996), and the rRNA sequences are in line with the established phylogeny, placing TAC125 near vibrios and Shewanella (Ivanova et al. 2004). In the same way, the number of tRNA genes is quite high (106 genes), a feature in common with that in vibrios and in Photobacterium profundum (Table 1). These genes are organized in long runs of repeated sequences. The longest contains 19 tRNA genes in a row, seven of which coding for an identical tRNA ${ }^{\text {glu }}$ (TTC anticodon), suggesting a slipped mispair mechanism of expansion in situations of rapid growth. Genomes with an origin of replication display a protein-coding gene distribution bias, with most essential genes located in the leading replication strand (Rocha and Danchin 2003). Interestingly, while the number of CDSs located in the leading strand of the chromosome is $61 \%, 72 \%$ of the tRNA genes are located in that strand. Because the speed of transcription/translation must be limited at low temperature, the large number of rRNA and tRNA genes may participate in the adaptation, allowing fast growth of the organism in the cold. TAC125 is similar to other bacteria in terms of number of tandem repeats. Several genes relevant to adaptation to cold conditions are clustered together in approximate repeats (Supplemental Fig. 2): genes coding for cold-shock proteins, nine paralogs of $\operatorname{cspA}$, as in E. coli (four in chrII, three of them clustered together), as well as genes coding for a class of putative short secreted proteins that could bind calcium, next to a divalent metal exporter system, most likely used in calcium export. Calcium is known to be involved in cold adaptation and formation of exopolysaccharides (EPS) in bacteria (Kierek and Watnick 2003; Dominguez 2004). The duplication in chrII of the ast operon may be involved in adaptation to cold and high osmolarity.

\section{Comparative genomics}

Of the 3488 identified protein coding genes (CDSs) (Table 1), a biological function, based on a classification scheme adapted from Riley (Riley 1993; Fang et al. 2005), has been assigned for $>65.6 \%$ (36.7\% with a final assignment and $28.9 \%$ with a putative role assignment). More than $63 \%$ of the $P$. haloplanktis CDSs are similar to Shewanella oneidensis genes (Heidelberg et al. 2002), of which $47 \%$ are found in synteny groups, making the comparison with this aquatic organism particularly revealing (Fig. 2A). These mesophilic marine bacteria, together with Vibrio vulnificus, share with $P$. haloplanktis several sodium-type flagellar proteins

\section{Genome Research}

www.genome.org 


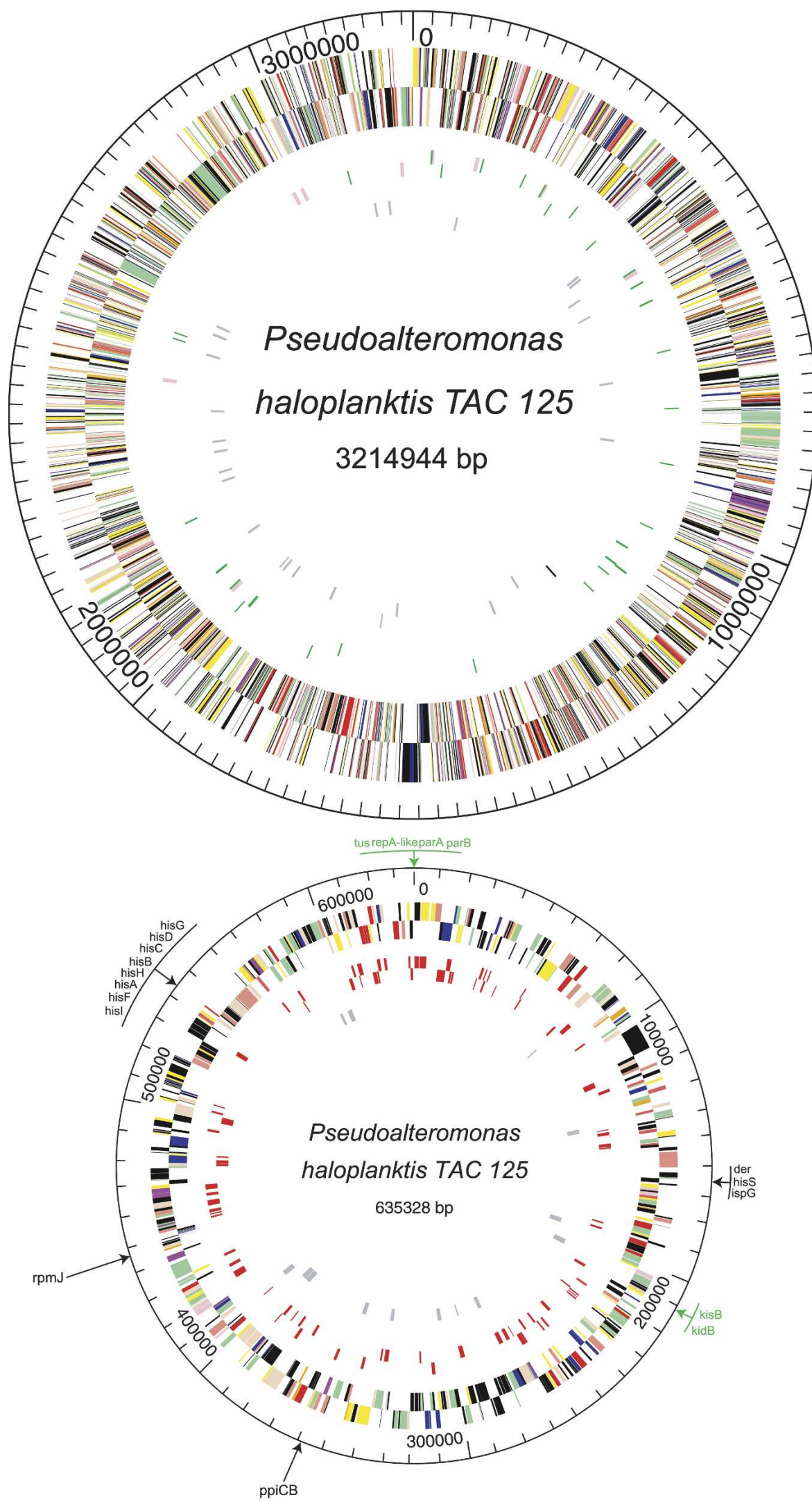

(mot genes), sodium-dependent transporters, gene clusters of type IV pilus and flagellin proteins, and some iron $\mathrm{ABC}$ transporter and ton $B$ systemdependent transport proteins (Fig. 2B; Supplemental Table 4C). A putative cold-shock RNA methyltransferase (PSHAb0516) and a cold-shock regulated carbon starvation protein A (PSHAb0210) have also been found in $S$. oneidensis and $V$. vulnificus. Other $P$. haloplanktis TonB-dependent receptors and calmodulin-like proteins have counterparts in $S$. oneidensis only, while $V$. vulnificus shares with $P$. haloplanktis several integrases/transposases, putative potassium channel proteins and metabolite exporters (Supplemental Table $4 \mathrm{~A}, \mathrm{~B})$. Gene content comparisons have also been performed with the two closest psychrophilic $\gamma$-proteobacteria, Idiomarina loihiensis and Photobacterium profundum (Fig. 2B): apart from the set of genes shared also with the marine bacteria, many TonB-dependent receptors are specific to $P$. haloplanktis and I. loihiensis, and two sodium-dependent carbohydrate transporters (a permease and a transporter) have been found in $P$. profundum only (Supplemental Table 4D,E). The set of genes common to P. haloplanktis and these two psychrophilic bacteria contain two copper resistance protein genes ( $о p A$ and $c o p B$ genes in chrII) (Supplemental Table 4F). These genes belong to a synteny group made of six genes with $I$. loihiensis and, interestingly, with the megaplasmid of Ralstonia

Figure 1. Circular representation of the Pseudoalteromonas haloplanktis genome. Circles display (from the outside): (1) predicted coding regions transcribed in the clockwise direction; (2) predicted coding regions transcribed in the counterclockwise direction. Genes displayed in 1 and 2 are color-coded according to different functional categories: salmon indicates amino acid biosynthesis; orange indicates purines, pyrimidines, nucleosides, and nucleotides; purple indicates fatty acid and phospholipid metabolism; light blue indicates biosynthesis of cofactors, prosthetic groups, and carriers; light green indicates cell envelope; red indicates cellular processes; brown indicates central intermediary metabolism; yellow indicates DNA metabolism; green indicates energy metabolism; pink indicates protein fate/synthesis; blue indicates regulatory functions; grey indicates transcription; teal indicates transport and binding proteins; and black indicates hypothetical and conserved hypothetical proteins. (3) tRNAs (green) and rRNA (pink) on chrl/genes similar to phage proteins (red) on chrll; (4) and tonB and tonBlike genes in grey. Chromosome II gene names similar to that of the R1 plasmid replication apparatus (unidirectional) are colored in green. 
A

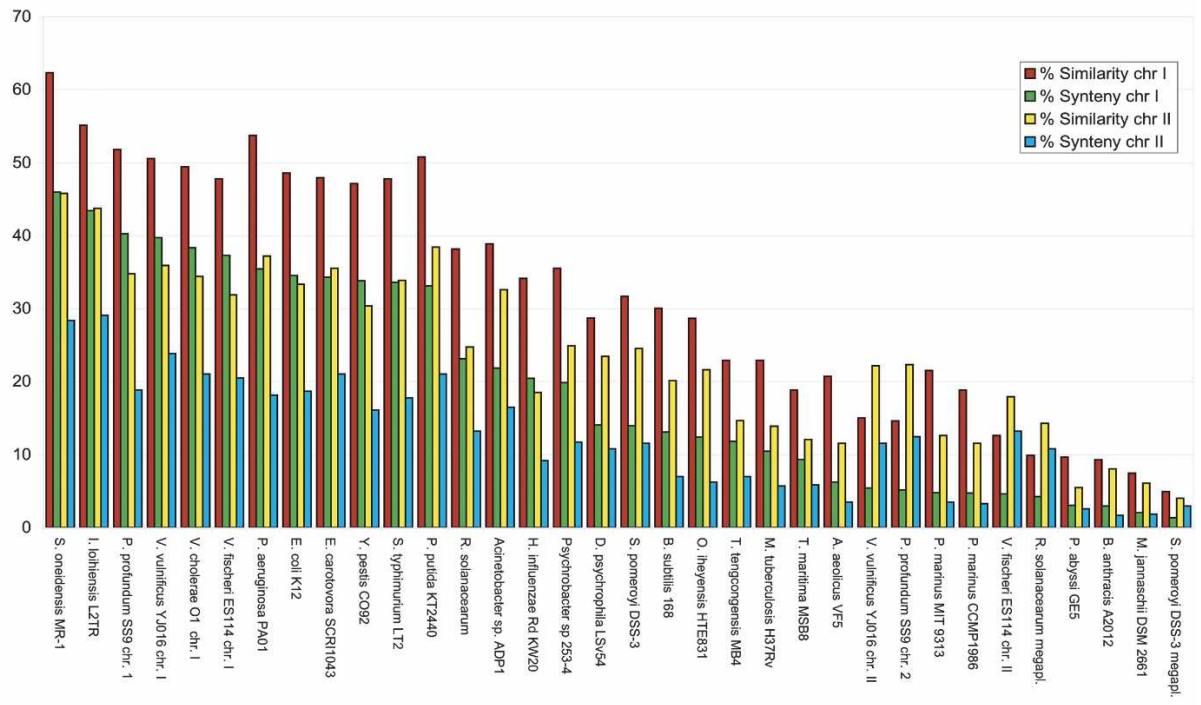

B
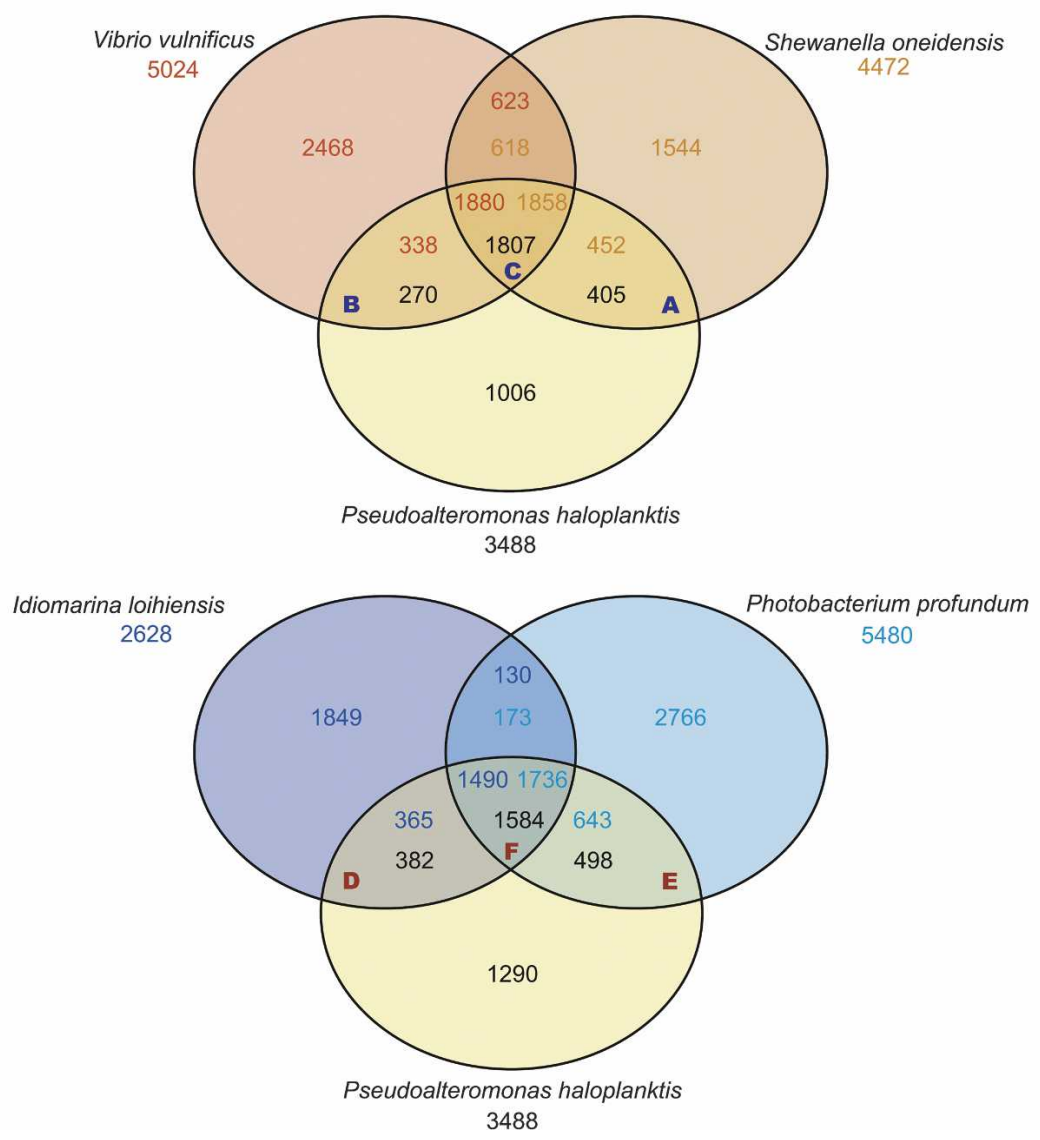

Figure 2. Putative orthologs and syntenies between the genome of $P$. haloplanktis and the genome of related bacteria. The alphabetic letters $\mathrm{A}$ to $\mathrm{F}$ refer to the Supplemental Table 4 (T4, A to F). (A) The percentage of $P$. haloplanktis genes homologs to a selection of 34 complete bacterial proteomes (i.e., $30 \%$ identity and a ratio of 0.8 of the length of the smaller protein to that of the larger one) is represented by red bars for chrl and by yellow bars for chrll. The percentage of $P$. haloplanktis genes in synteny groups with a selection of 34 complete bacterial genomes is represented by green bars for chrl and by blue bars for chrll. The closest organism is S. oneidensis. (B) Comparison of the gene content of Pseudoalteromonas haloplanktis, Shewanella oneidensis, Vibrio vulnificus, Photobacterium profundum, and Idiomarina ioihiensis. Putative orthologs are defined as genes showing a minimum of 30\% identity and a ratio of 0.8 of the length of the smaller protein to that of the larger one, or as two genes included in a synteny group. The intersections between the three circles give the number of genes found in the two or three compared species. Genes outside these areas are specific to the corresponding organism. The total number of annotated genes is also given under each species name. 
solanacearum. They are also found in other distant cold marine bacteria such as Psychrobacter sp. and Silicibacter pomeroyi (in its megaplasmid; Supplemental Table 5).Two synteny groups (a potassium efflux system and an urease operon) are found with $S$. pomeroyi only. A total of $133 \mathrm{P}$. haloplanktis genes (73 hypothetical), including several insertion sequences and genes coding for TonB-dependent receptors, have not been found in the genome of the cold-adapted marine bacteria used for comparison (Supplemental Table 6). In addition, a prophage region (50 kb long, between genes PSHAa1505 and PSHAa1558) is specific to P. haloplanktis. We also identified one specific region in chrI coding for several calcium-dependent proteins, as well as a specific gene in chrII that may regulate cell volume and resistance to cold conditions (PSHAb0555).

\section{General features of the proteome}

Global properties of the proteins at the level of individual amino acids and motifs integrate all kinds of selection pressure associated to adaptation to cold. The pattern of amino acid distribution in $\gamma$-proteobacteria from different biotopes (Supplemental Fig. 3) displays an overall trend similar in the various genomes of interest, with leucine (L) being most abundant, while tryptophan (W), cysteine $(\mathrm{C})$, histidine $(\mathrm{H})$, and to a lesser extent methionine $(\mathrm{M})$ are used infrequently. The proteome of the thermophilic genomes looks significantly different from that of the mesophilic and psychrophilic counterparts (strong avoidance of glutamine $[\mathrm{Q}]$ in thermophilic species, preference for alanine $[\mathrm{A}]$ in mesophilic and psychrophilic species, except in Oceanobacillus iheyensis). The amino acid distribution in mesophilic and psychrophilic species display a few noteworthy differences specifically relevant to growth in the cold (in particular in the relative abundance of $\mathrm{N}$ and Q) (Supplemental Fig. 3). Using correspondence analysis (CA) (Benzécri 1984) coupled to dynamic clustering (Delorme and Henaut 1988), to identify subtle differences in this cluster of related objects, five classes with close amino acid composition were found (Fig. 3): (1) integral inner membrane proteins ( 12\%); (2) proteins involved in the metabolism of small molecules (25\%); (3) associated to information transfer pathways (21.5\%); (4) associated to the outer membrane or secreted (21.5\%); and (5) with unknown functions, or likely to be of phage origin (20\%). This biological consistency demonstrates that a relationship exists between amino acid composition and the role of the protein inside the cell. The two first biases have been previously identified: They are driven by the membrane compartmentalization of some proteins and by the $\mathrm{G}+\mathrm{C}$-content of codons (Pascal et al. 2005). In contrast, the bias scattering proteins along the third factorial axis was unexpected. It discriminated proteins in P. haloplanktis TAC125 according to their asparagine $(\mathrm{N})$ content. This small hydrophilic uncharged amino acid carries an amide group that is often thermolabile (Zhou et al. 2000; Stratton et al. 2001; Weintraub and Manson 2004). Analysis of this remarkable Ndriven bias was further submitted to CA using the pool of two psychrophilic (Desulfotalea psychrophila and P. haloplanktis), two mesophilic (E. coli K-12 and Bacillus subtilis) and two thermophilic (Aquifex aeolicus and Thermotoga maritima) bacteria. An Ndriven bias was observed in proteins from the psychrophiles, differentiating them from their mesophilic and thermophilic counterparts (Supplemental Fig. 4). The proteins responsible for the bias belong to the following structures or processes: motility of the organism, cell wall, outer membrane, transport, sensor activity, adaptation to atypical conditions, and secretion. Some proteins of DNA metabolism (replication, packaging, segregation,

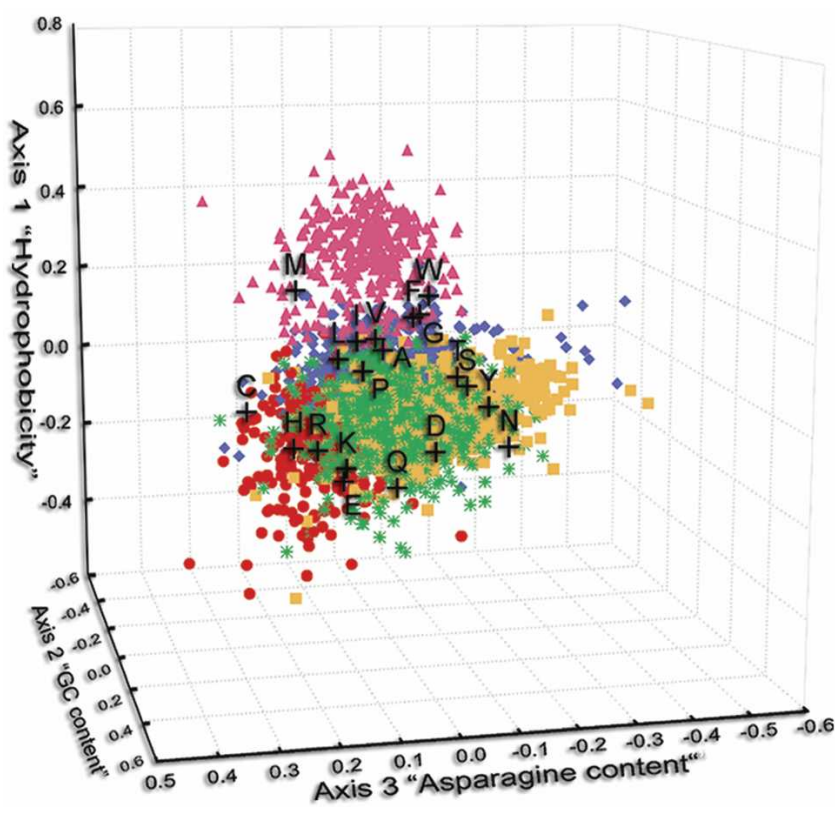

Figure 3. Distribution of the protein sequences on the CA space determined by the three first factors. The first one discriminates proteins by their hydrophobicity; the second one, by the GC content of genes coding for them; and the third one, by their asparagine content. Five classes of proteins are found by clustering method (see "General Features of Proteome") and are represented: (1) IIMP by pink triangles, (2) proteins involved in the metabolism of small molecules by blue diamonds, (3) proteins associated to information transfer pathways by red circles, (4) proteins associated to the outer membrane or secreted by green stars, and (5) proteins with unknown functions, or likely to be of phage origin, by yellow squares. Amino acids are represented by black pluses.

restriction/modification, proof-reading, and repair) and RNA metabolism are also present. Asparagine residues often undergo deamidating cyclisation, a process extremely sensitive to temperature (Daniel et al. 1996). The P. haloplanktis TAC125 proteome is enriched in $\mathrm{N}$ residues compared with counterparts that prefer growth at higher temperature, making it an organism of choice for foreign protein production when deamidation ought to be put to a minimum (Weintraub and Manson 2004).

\section{RNA folding and metabolism}

The genome of $P$. haloplanktis TAC125 contains 19 genes presumably coding for known RNA binding proteins or RNA chaperones. The most unexpected feature of the genome is the prominent absence of a RNA/nucleoid-associated cold-shock gene ubiquitous in $\gamma$-proteobacteria, hns. Analysis in silico failed to uncover a H-NS-like protein gene even when using the highly relaxed comparison criteria that uncovered counterparts in bacteria phylogenetically distant from E. coli (Tendeng and Bertin 2003). In contrast, the genes coding for all other nucleoid-associated proteins such as HU, IHF, FIS, and Hfq are present in the genome. The existence of a complete set of genes (including hns) was also observed in other marine and cold-adapted bacteria, including $S$. oneidensis (Heidelberg et al. 2002) and D. psychrophila (Rabus et al. 2004). In vivo complementation of a hns defect of $E$. coli at room temperature led us to repeatedly isolate clones coding for the counterpart of csrA as an efficient complementation of the hns defect of E. coli. The lack of the hns-encoding gene in the psychrophilic $P$. haloplanktis genome shows that H-NS is not sufficient to promote growth at low temperature and that its role is 
connected to that of the regulatory protein/RNA complex CsrA/ CsrB (Fig. 4). The importance of control of RNA folding and degradation at low temperature is visible in the presence of many RNA helicases (three copies of rhlE, two in chrI and one in chrII, and possibly a fourth one, PSHAa0641, and two copies of srmB, instead of one in E. coli). Interestingly, in contrast with the situation reported for Oleispira antarctica (Ferrer et al. 2004) the groES groEL genes from TAC125 did not permit growth of E. coli at low temperature. Other factors are therefore important for cold adaptation in the present organism.

Several RNA motifs indicating the presence of RNA-coding genes have been found in chrI using the Rfam databank (see Methods): a tmRNA at position 2,231,297 bp, the RNA component of RNase P at position 2,674,641 bp, the t44 RNA (of unknown function), and three riboswitch structures (Nudler and Mironov 2004), a lysine riboswitch just in front of dapA gene (at position $189,092 \mathrm{bp}$ ); the RFN element, located at 1283,710 near ribB gene; and the "ubiquitous" TPP riboswitch (THI element) at 496,922 bp (upstream of the thiC gene).

\section{Response to oxygen and reactive oxygen species}

The solubility of gasses increases rapidly at low temperature. This is the case of dioxygen, which is a very reactive molecule. We expected that the proteome would comprise a vast arsenal of enzymes active against $\mathrm{H}_{2} \mathrm{O}_{2}$ and superoxide. This was the more so because the organism is indeed remarkably resistant to $\mathrm{H}_{2} \mathrm{O}_{2}$ (Supplemental Fig. 5). Surprisingly, we found only the gene counterpart coding for the iron superoxide dismutase $(\operatorname{sodB})$ and only one clear catalase $(k a t B)$ located in chrII, with a possible paralog in chrI (PSHAa1737). Furthermore, while the oxygen responding OxyR control is present, the SoxR regulation is absent.

This unexpected finding was explained when we discovered that $P$. haloplanktis TAC125 lacks a series of activities that result in reactive oxygen species (ROS) production. Despite the avail-
A

C

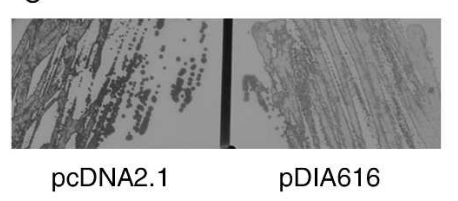

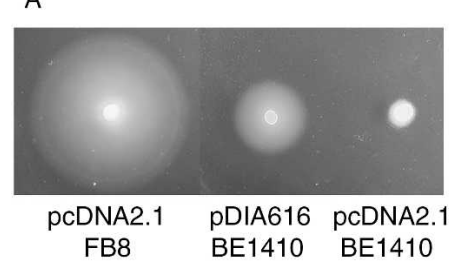

B

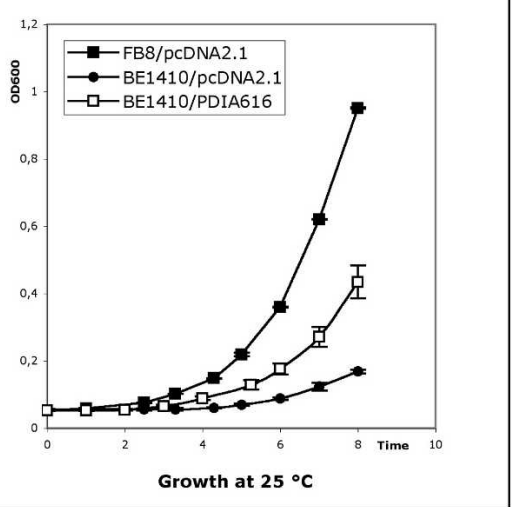

Figure 4. hns complementation in $E$. coli with $P$. haloplanktis csrA. A DNA fragment encompassing $P$. haloplanktis gene csrA with $140 \mathrm{bp}$ of its upstream region was cloned into plasmid pCDNA2.1 (pDIA616) and the phenotypes of the resulting E. coli hns transformants were compared to the hns mutant (BE1410) and to the wild-type FB8 parental strain. (A) Motility assay: Partial motility is restored with the csrA gene of $P$. haloplanktis. Other phenotypes such as serine sensitivity of the hns mutant are restored by the $\operatorname{csr} A$ gene as well. $(B)$ Growth at $25^{\circ} \mathrm{C}$ : overnight cultures were diluted to $0.05 \mathrm{OD}_{600}$ in $\mathrm{LB}$ medium with ampicillin $100 \mu \mathrm{g} / \mathrm{mL}$, and growth was monitored (as in Dersch et al. 1994). Significant improvement of growth is witnessed with the csrA gene of P. haloplanktis. (C) CsrAdependent storage of glycogen in E. coli MG1655. Expression of $P$. haloplanktis csrA inhibits glycogen storage (light iodine color, right panel). ability of molybdate in sea water (Hille 2002), P. haloplanktis TAC125 entirely lacks molybdopterin metabolism: not only are the biosynthetic and transport gene absent but genes coding for enzymes using the cofactor are also missing (e.g., TMAO reducoxido-reductase YedY) (Loschi et al. 2004). All related organisms such as the vibrios or Shewanella have molydopterin metabolism, almost all Bacteria and Eukarya. The cells, however, mus cope with increased oxygen solubility and inevitable interaction with reduced iron, leading to the deleterious Fenton reaction and . A way for the cells to protect their metabolism against those is to use dioxygen directly. This is seen in the large number of putative dioxygenases present in both chromosomes (Table 2). that also play a role to increase membrane fluidity at low temperature.

Furthermore, the protective role of methionine against ROS is enhanced by the existence of two MsrA proteins, instead of one as is usual, together with a fused MsrA-MsrB protein, a rare situ, found in Nitrosomonas europaea. Interestingly, one MsrA , PSHAa1583, not present in $P$. profundum, exists in develop preferentially at low temperature. A further sign that the bacteria cope with the specific problems posed by ROS is the number of proteins involved in scavenging chemical groups affected: peroxiredoxins such as alkyl hydroperoxide reductase AhpC, AhpCB, thiol-specific cytoplasmic peroxidase BcpA; thiolperiplasmic peroxidase Tpx, and their coupled flavoproprotect against the inevitable consequences of the Fenton reacpresent. Furtherm control system that would limit the concentration of copper in the cell $\left(\mathrm{Cu}^{2+}\right.$ is particularly reactive toward oxygen) involves at least two transport systems to expel copper out of the cell (CusA, CopAB, in chrI and PSHAb0008, PSHAb0009, CopB, CopA, and PSHAb0325 in chrII), a periplasmic disulfide reductase (DipZ), and a periplasmic putative laccase (PcoA) that could chelate copper ions while also acting as a dioxygenase.

Finally, an interesting gene cluster involved in fatty acid metabolism PSHAa0894-0910 is absent from other $\gamma$-proteobacteria, but is largely present in Mycobacterium tuberculosis (where it may have a protective role against ROS, contributing to virulence). In short, $P$. haloplanktis TAC125 is remarkably well adapted to protection against ROS under cold conditions, a feature that could be very useful for expression of foreign proteins in the cold.

\section{Metabolic features}

Marine bacteria are facing a medium generally unbalanced in terms of carbon, nitrogen, and phosphorous supply (Moran et al. 2004) but are not depleted

\section{Genome Research}

www.genome.org 
The Pseudoalteromonas haloplanktis TAC125 genome

Table 2. Proteins involved in cold/salt adaptation

\begin{tabular}{|c|c|c|c|c|}
\hline Locus & $\begin{array}{l}\text { Proteins } \\
\text { size }\end{array}$ & $\begin{array}{l}\text { Gene } \\
\text { name }\end{array}$ & Chr. & Description \\
\hline \multicolumn{5}{|l|}{ Cold-shock protein } \\
\hline PSHAa0109 & 463 & $d b p A$ & 1 & Putative ATP-dependent RNA helicase; putative cold-shock protein \\
\hline PSHAa0114 & 421 & $\operatorname{rhlB}$ & 1 & ATP-dependent RNA helicase, putative cold-shock protein \\
\hline PSHAa0990 & 617 & deaD & 1 & ATP-dependent RNA helicase, cold-shock protein A \\
\hline PSHAa1184 & 68 & $\operatorname{cspC}$ & 1 & Cold-shock protein, transcription antiterminator \\
\hline PSHAa1222 & 209 & grpE & 1 & $\begin{array}{l}\text { Putative member of the DnaK/Dnal/GrpE foldase complex (heat/cold-shock protein; } \\
\text { involved in thermal regulation of folding) }\end{array}$ \\
\hline PSHAa1600 & 204 & & 1 & Putative cold-shock DNA-binding domain \\
\hline PSHAa1726 & 73 & $\operatorname{csp} D$ & 1 & Nucleic acid-binding domain, cold-shock RNA chaperone \\
\hline PSHAa2978/2979/2980 & 70 & cspE & 1 & RNA chaperone, transcription antiterminator \\
\hline PSHAa2981 & 750 & & 1 & Cold-shock RNÁse R \\
\hline PSHAb0078 & 63 & $\operatorname{csp} X$ & 2 & Cold-shock protein \\
\hline PSHAb0210 & 491 & CstA & 2 & Cold-shock regulated carbon starvation protein $\mathrm{A}$ \\
\hline PSHAb0384/0386/0387 & 70 & $\operatorname{csp} X$ & 2 & Cold-shock protein \\
\hline PSHAb0516 & 171 & & 2 & Putative cold-shock RNA methyltransferase \\
\hline \multicolumn{5}{|l|}{ Dioxygenases } \\
\hline PSHAa0187 & 235 & & 1 & Conserved protein of unknown function; putative dioxygenase \\
\hline PSHAa0570 & 140 & & 1 & Conserved protein of unknown function; putative glyoxalase domain \\
\hline PSHAa0900 & 297 & $\operatorname{tes} B$ & 1 & Putative dioxygenase \\
\hline PSHAa0904 & 372 & & 1 & Putative dioxygenase \\
\hline PSHAa2137 & 365 & & 1 & Putative protein with ferredoxin subunits; putative dioxygenase \\
\hline PSHAa2147 & 309 & & 1 & Putative taurine dioxygenase \\
\hline PSHAa2168 & 351 & melA & 1 & 4-hydroxyphenylpyruvate dioxygenase (4HPPD) (HPD) (HPPDase) \\
\hline PSHAa2449 & 158 & & 1 & Conserved protein of unknown function; putative dioxygenase domain \\
\hline PSHAb0029 & 167 & & 2 & Putative enzyme; dioxygenase superfamily \\
\hline PSHAb0041 & 119 & & 2 & Putative enzyme; dioxygenase superfamily \\
\hline PSHAb0115 & 128 & & 2 & Putative enzyme; dioxygenase superfamily \\
\hline PSHAb0338 & 434 & $h m g A$ & 2 & Homogentisate 1,2-dioxygenase \\
\hline \multicolumn{5}{|l|}{ Fatty acids (desaturase) } \\
\hline PSHAa0567 & 271 & & 1 & Conserved protein of unknown function; putative sterol desaturase family protein \\
\hline PSHAa1269 & 351 & & 1 & Putative fatty acid desaturase \\
\hline PSHAa2897 & 378 & & 1 & Putative long chain acyl-CoA desaturase \\
\hline PSHAb0225 & 264 & & 2 & Putative C-5 sterol desaturase \\
\hline \multicolumn{5}{|l|}{ Salt adaptation } \\
\hline PSHAa0020 & 459 & $\operatorname{trk} A$ & 1 & Potassium transport inner membrane protein subunit; involved in osmoprotection \\
\hline PSHAa0208 & 257 & cys $Q$ & 1 & $3^{\prime}, 5^{\prime}$ adenosine diphosphate $3^{\prime}$ phosphatase, sodium sensing \\
\hline PSHAa0325 & 188 & osmY & 1 & Putative hyperosmotically inducible periplasmic protein \\
\hline PSHAa0326 & 53 & & 1 & Putative low-temperature and salt-responsive protein \\
\hline PSHAa0396 & 273 & mscs & 1 & Putative mechanosensitive channel protein; protection against hypo-osmotic shock \\
\hline PSHAa0687 & 255 & surE & 1 & Putative acid phosphatase SurE; protection against osmotic shock \\
\hline PSHAa0833 & 512 & putP & 1 & Major sodium/proline symporter; protection against osmotic shock \\
\hline PSHAa1072 & 522 & & 1 & Putative glycine betaine transporter \\
\hline PSHAa1226 & 439 & & 1 & Putative $\mathrm{Na}+/ \mathrm{H}+$ antiporter \\
\hline PSHAa1436 & 531 & & 1 & Putative choline/betaine transporter \\
\hline PSHAa1625 & 403 & & 1 & Putative sodium $\mathrm{ABC}$ exporter, permease component \\
\hline PSHAa1626 & 263 & & 1 & Putative sodium ABC exporter, ATP-binding component \\
\hline PSHAa1678 & 675 & pre & 1 & $\begin{array}{l}\text { Periplasmic C-terminal protease with specificity for nonpolar C termini; protection } \\
\text { against osmotic shock }\end{array}$ \\
\hline PSHAa1679 & 213 & proQ & 1 & Putative post-translational activator of ProP expression; sensing osmotic shock \\
\hline PSHAa2041 & 676 & & 1 & Putative choline/betaine transporter \\
\hline PSHAa2202 & 144 & osmC & 1 & Osmotically inducible protein C; protection against oxidative stress \\
\hline PSHAa2243 & 102 & bolA & 1 & Regulator involved in adaptation to osmotic shock \\
\hline PSHAa2252 & 561 & & 1 & Putative voltage-gated CIC-type chloride channel ClcA \\
\hline PSHAa2274 & 660 & $m d o B$ & 1 & Putative phosphoglycerol transferase; shape adaptation to osmotic shock \\
\hline PSHAa2849 & 434 & envZ & 1 & Sensor histidine kinase, senses osmolarity \\
\hline PSHAa2850 & 240 & $\mathrm{OmpR}$ & 1 & Response regulator for adaptation to osmolarity \\
\hline PSHAb0106 & 576 & CVRA & 2 & Putative $\mathrm{Na}+/ \mathrm{H}+$ antiporter; adaptation to hypo-osmotic shock \\
\hline PSHAa0176 & 289 & & 2 & Putative mechanosensitive channel protein; protection against hypo-osmotic shock \\
\hline PSHAb0127 & 1536 & $g / t B$ & 2 & Glutamate synthase, large subunit, GOGAT \\
\hline PSHAb0128 & 497 & gltD & 2 & Glutamate synthase, small subunit \\
\hline PSHAb0261 & 534 & betc & 2 & Putative choline dehydrogenase \\
\hline PSHAb0357 & 639 & dnak & 2 & Chaperone protein DnaK; involved in protection \\
\hline \multicolumn{5}{|l|}{ Against osmotic shock } \\
\hline PSHAb0381 & 129 & betC & 2 & Putative osmC-like protein \\
\hline PSHAb0418 & 556 & betA & 2 & Putative choline dehydrogenase \\
\hline PSHAb0419 & 500 & bet $B$ & 2 & $\mathrm{NAD}^{+}$-dependent betaine aldehyde dehydrogenase \\
\hline PSHAb0420 & 197 & betl & 2 & Putative transcriptional repressor for the cellular response to osmotic stress \\
\hline
\end{tabular}


Médigue et al.

Table 2. Continued

\begin{tabular}{|c|c|c|c|c|}
\hline Locus & $\begin{array}{l}\text { Proteins } \\
\text { size }\end{array}$ & $\begin{array}{l}\text { Gene } \\
\text { name }\end{array}$ & Chr. & Description \\
\hline \multicolumn{5}{|c|}{ Against osmotic shock } \\
\hline PSHAb0426 & 489 & & 2 & $\begin{array}{l}\text { Putative succinylglutamic semialdehyde dehydrogenase; may be involved in adaptation } \\
\text { to high osmolarity }\end{array}$ \\
\hline PSHAb0427 & 345 & & 2 & Putative arginine succinyltransferase; may be involved in adaptation to high osmolarity \\
\hline PSHAb0428 & 402 & & 2 & Putative acetylornithine transaminase; may be involved in adaptation to high osmolarity \\
\hline \multicolumn{5}{|c|}{ Helicases $[\mathrm{DEA}(\mathrm{DH})]$} \\
\hline PSHAa0109 & 463 & $d b p A$ & 1 & $\begin{array}{l}\text { Putative ATP-dependent RNA helicase; putative cold-shock protein; could be specific for } \\
\text { rRNA folding }\end{array}$ \\
\hline PSHAa0114 & 421 & $r h / B$ & 1 & $\begin{array}{l}\text { ATP-dependent RNA helicase with nucleoside triP hydrolase domain, putative cold-shock } \\
\text { protein }\end{array}$ \\
\hline PSHAa0510 & 409 & $\operatorname{srm} B$ & 1 & ATP-dependent RNA helicase \\
\hline PSHAa0641 & 433 & & 1 & ATP-dependent RNA helicase (rhIE-like); DEAD-box protein family \\
\hline PSHAa0990 & 617 & deaD & 1 & ATP-dependent RNA helicase, cold-shock protein A \\
\hline PSHAa1144 & 1298 & hrрA & 1 & Helicase, ATP-dependent \\
\hline PSHAa1432 & 441 & $\operatorname{srm} B$ & 1 & ATP-dependent RNA helicase, DEAD box family \\
\hline PSHAa1522 & 415 & & 1 & Conserved protein of unknown function \\
\hline PSHAa1930 & 467 & rhIE & 1 & Putative ATP-dependent RNA helicase with P-loop hydrolase domain \\
\hline PSHAa1991 & 692 & $\operatorname{din} G$ & 1 & Putative ATP-dependent helicase DinG \\
\hline PSHAa2216 & 809 & hrрB & 1 & ATP-dependent helicase \\
\hline PSHAa2480 & 831 & $r n r$ & 1 & RNase R, 3'-5' exoribonuclease \\
\hline PSHAa2572 & 608 & recQ & 1 & ATP-dependent DNA helicase \\
\hline PSHAa2624 & 965 & hерA & 1 & RNA polymerase associated protein (ATP-dependent helicase HepA) \\
\hline PSHAa2762 & 676 & rep & 1 & Rep helicase, a single-stranded DNA-dependent ATPase \\
\hline PSHAa2983 & 435 & rhle & 1 & $\begin{array}{l}\text { DEAD-box protein family; putative ATP-dependent RNA helicase with P-loop hydrolase } \\
\text { domain }\end{array}$ \\
\hline PSHAb0003 & 1049 & & 2 & Putative DNA helicase with DEAD/DEAH box helicase domain \\
\hline PSHAb0039 & 1352 & & 2 & Putative protein with DEAD/DEAH box helicase domain \\
\hline PSHAb0119 & 649 & & 2 & Putative ATP-dependent DNA helicase (recQ-like) \\
\hline PSHAb0411 & 434 & rhIE & 2 & $\begin{array}{l}\text { Putative ATP-dependent RNA helicase with P-loop hydrolase domain; DEAD-box protein } \\
\text { family }\end{array}$ \\
\hline PSHAb0497 & 639 & yoaA & 2 & $\begin{array}{l}\text { Putative ATP-dependent helicase YoaA with nucleotide triphosphate hydrolase domain, } \\
\text { SOS repair, DinG family }\end{array}$ \\
\hline
\end{tabular}

in sulfur sources. Strain TAC125 is adapted to fast growth, suggesting that it regularly encounters a fairly rich medium (this is probably due to its propensity to make a water/air biofilm [see below], allowing it to live in region full of plankton debris). Excess of several easily metabolized carbon sources present simultaneously is unlikely, making catabolite repression the exception rather than the rule. Indeed, $P$. haloplanktis TAC125 is lacking the cAMP-CAP complex that regulates carbon availability in related organisms such as vibrios and Shewanella. Furthermore, in contrast to many $\gamma$-proteobacteria (including vibrios), it does not possess a phosphoenolpyruvate-dependent phosphotransferase system for the transport and first metabolic step of carbohydrate degradation. This accounts for its lack of growth on glucose, likely to be phosphorylated by glucokinase (PSHAa1364). When oxygen is present at a high level, the presence of glucosephosphate isomerase might drive the Embden Meyerhof pathway and subsequently activate NADPH-dependent aldose reductase (PSHAa2392). This would affect the polyol pathway, lowering the amount of NADPH available for the reduction of oxidized glutathione by glutathione reductase. Indeed, growth is inexistent on glucose unless tyrosine is supplemented to the medium (data not shown). The counterpart of PSHAa2392 has been implicated in a process controlling tyrosine bradytrophy in E. coli (Timms and Bridges 1998).

An essential step for biomass construction is formation of pyruvate, which, because of the absence of the PTS, must go through an alternative pathway starting with pyruvate kinase. In contrast to $E$. coli, with two such enzymes, and vibrios, with three, TAC125 possesses only one pyruvate kinase. Interestingly, it is homologous to the cold-adapted PykA enzyme of $E$. coli. This is further in line with gluconate as a preferred carbon source, providing pyruvate directly through the Entner-Doudoroff pathway (Edd, Eda), which also provides the level of NADPH needed for protection against oxygen toxicity. As in vibrios, phosphoenolpyruvate synthase ( $p p s A$ ) and phosphoenolpyruvate carboxylase $(p p c)$ genes are located in chrII. However, $p p s A$ is located in chrI in $P$. profundum.

TAC125 grows in minimal medium under anaerobic conditions (data not shown), in line with the presence of the fur gene, while the putative aspartate ammonia lyase PSHAa0048 would provide the needed fumarate electron acceptor.

In contrast, the metabolism of nitrogen appears to be highly similar to that in phylogenetically related organisms and be controlled by a phosphorylation cascade involving PtsP (a homolog of the PTS enzyme PtsI) that phosphorylates PtsO and the regulator PtsN, controlling all sigma54-dependent operons. Arginine catabolism could provide a direct source of ammonia under nitrogen-limiting conditions, through the AST pathway, while providing metabolites for adapation to cold (Schneider et al. 1998). The organism can metabolize $\mathrm{N}$-acetyl-glucosamine, a carbon and nitrogen source ubiquitously present in marine environment (Riemann and Azam 2002). In the same way, phosphate input in metabolism is controlled by the counterparts of PhoB, PhoR, and PhoU, with several putative transport systems, including one of high affinity.

Most coenzymes can be synthesized in the organism except coenzyme B12 and, as discussed, molybdopterin. There does not appear to exist a selenium metabolism, in line with the high

\section{Genome Research}

www.genome.org 
reactivity of that atom toward oxygen. Other marine bacteria (including the closest one, $S$. oneidensis) do have a selenium metabolism.

\section{Growth, yield, and adaptation to salt}

A remarkable feature of TAC125 is that, when provided with sufficient nutrients and aeration, it grows to very high density under laboratory settings, even at $0^{\circ} \mathrm{C}$. The very high growth yield indicates that respiration must be particularly efficient in this bacterium. The cells are well adapted to salt, and although they can grow in low osmolarity media, optimal growth is between $1.5 \%$ and $3.5 \% \mathrm{NaCl}$. We looked for systems that would account for controlling osmolarity in the cell. The common trehalose system does not seem to be present. In contrast, chrII harbors two copies of a choline dehydrogenase (PSHAb0261 and PSHAb0418) for synthesis of glycine betaine, an extremely efficient osmoprotectant (Felitsky et al. 2004). Along the same line, GOGAT glutamate synthase is coded in that same chromosome, allowing synthesis of glutamate that, as potassium glutamate, is the most common response of bacteria to increased osmolarity (Table 2; Lee and Gralla 2004).

All autonomous organisms have at least one pathway to degrade $S$-adenosylhomocysteine (AdoHcy). The MtnN(Pfs)/LuxS pathway leads to synthesis of the quorum sensing (QS) effector autoinducer-2 (AI-2). Xanthomonadales and Pseudomonadales aside, all $\gamma$-proteobacteria sequenced use that pathway. LuxS, responsible for the last enzymatic step of AI-2 synthesis is present in bacteria closest to TAC125, and AI-2 produced by heterologous organisms triggers luminescence in reporter strains. The $m t n N$ gene is present in TAC125. We failed, however, to identify the luxS gene. We looked further for other genes involved in AdoHcy degradation and recycling to homoserine lactones or autoinducer CAI-1. Among other systems, involving quinolones, cyclic dipeptides, or indole, none appears to be present, and in assays, using Photorhabdus luminescens as reporter TAC125 supernatant did not trigger luminescence. This does not, however, exclude the presence of less well known QS systems: gene PSHAa0159 codes for a multidomain putative aconitate hydratase that may use aconitate as an iron-sulfur cluster-dependent signal in stationary phase (Kiley and Beinert 2003). Furthermore, TAC125 possesses several enoyl-CoA hydratase-like genes that may be involved in synthesis of a diffusible signaling factor as in plant pathogenic $\gamma$-proteobacteria (Barber et al. 1997).

\section{Membranes, motility, biofilms, and secretion}

$P$. haloplanktis TAC125 deals with the membrane fluidity challenge at low temperature by lipid desaturases, which simultaneously protect against dioxygen (Table 2). Two clusters of genes, absent in the closest genomes, may be involved in the degradation of steroids or hopanoids, membrane rigidifying molecules present in the environment of heterotrophic bacteria. Protein export from the cytoplasm is similar to that of proteobacteria, with the long form of SecE. Type II secretion is functional (GSP proteins are present) as is the TAT export system. In contrast, type III secretion is absent. TAC125 possesses two gene clusters in chrI and one in chrII for the biosynthesis of type IV pili and of curli, respectively. Furthermore, chrII encodes elements of the new pathway involved in secretion of a specific amylase composed of a signal peptide, the mature enzyme, and a long Cterminal propeptide without foldase function or action on amylase activity (Claverie et al. 2003). Amylase secretion required two accessory proteins, PSHAb0130 (possibly an outer membrane associated protein) and PSHAb0132, coding for a conserved secreted protein present in several phytopathogenic $\gamma$-proteobacteria. Interestingly, the neighboring glutamate synthesis genes were essential to allow amylase secretion when reconstructed in E. coli.

$P$. haloplanktis has several genes and operons that may play an important role in colonization of both biotic and abiotic surfaces. In particular, up to 16 genes involved in the synthesis of mannose-sensitive agglutinin are located on chrI. These genes have been recently demonstrated to facilitate adhesion to the chitin surface in $V$. cholerae (Meibom et al. 2004). When investigating the formation of biofilms on solid surfaces (many genes are compatible with synthesis of a biofilm such as production of EPS), we did not observe synthesis of a strong biofilm. In contrast, the air-water interface was rapidly occupied by a dense layer of compact cells (Supplemental Fig. 6), suggesting that, for this organism, this is the normal way to concentrate cells and occupy a biotope. The formation of such a biofilm compatible with life in water and scavenging of organic particles that concentrate in the foam of waves has been recently demonstrated in $V$. parahaemolyticus (Enos-Berlage et al. 2005). Genes for the synthesis of polar flagellum are present, and these appendages are visible under the microscope. In salty water the cells are highly motile. However, in contrast to the situation with several vibrios, pseudomonads, and related bacteria, the cells have a reduced motility in low salt media, while they still grow well under such conditions (Supplemental Fig. 7). In minimal medium, the strain grew in a large range of $\mathrm{NaCl}$ concentration ( $0 \%$ to up $11 \%$ $\mathrm{NaCl})$. In rich media, however, the growth of the strain is remarkably sensitive to the presence of salt. At $20^{\circ} \mathrm{C}$, no growth occurs in the absence of $\mathrm{NaCl}$. In remarkable contrast, slow but significant growth is observed at $4^{\circ} \mathrm{C}$ in the absence of salt, suggesting some adaptation to ice or melting ice water.

\section{Conclusions}

P. haloplanktis TAC125 has found many unexpected solutions to cope with cold. Not only does it grow fast under such conditions, but it displays remarkable resistance to ROS. Moreover, as seen in silico with its proteome composition, it provides a way to resist to the aging features involving asparagine cyclisation and deamidation. This makes this bacterium not only a model for the study of adaptation to cold marine conditions but also a promising tool for biotechnology production of proteins.

\section{Methods}

\section{Bacterial strains, growth media, and assays}

The P. haloplanktis strain TAC125 is deposited and available at the Institut Pasteur Collection (CIP). Escherichia coli strains used in this work are strains MG1655, FB8, and its hns defective counterpart BE1410 (Laurent-Winter et al. 1997). TAC125 bacteria were grown in TYP rich media: $16 \mathrm{~g} / \mathrm{L}$ yeast extract (DIFCO) and $16 \mathrm{~g} / \mathrm{L}$ bacto-tryptone (DIFCO) supplemented with $\mathrm{NaCl}$ as required. For growth on specific carbon sources $(0.4 \%)$, the following minimum medium was used: $10 \mathrm{~g} / \mathrm{L} \mathrm{Na}_{2} \mathrm{HPO}_{4}, 3 \mathrm{~g} / \mathrm{L} \mathrm{KH}_{2} \mathrm{PO}_{4}$, $1 \mathrm{~g} / \mathrm{L} \mathrm{K}_{2} \mathrm{SO}_{4}, 20 \mathrm{~g} / \mathrm{L} \mathrm{NaCl}, 0.4 \mathrm{~g} / \mathrm{L} \mathrm{MgSO}{ }_{4} \cdot 7 \mathrm{H}_{2} \mathrm{O}, 0.1 \mathrm{~g} / \mathrm{L} \mathrm{CaCl}_{2}$, $0.018 \mathrm{~g} / \mathrm{L} \mathrm{FeSO}_{4} \cdot 7 \mathrm{H}_{2} \mathrm{O}$, and $3 \mathrm{~g} / \mathrm{L} \mathrm{NH}_{4} \mathrm{Cl}(\mathrm{pH} 7)$. Motility assay of $E$. coli cells with plasmids carrying $P$. haloplanktis genes was performed on semisolid plates with $0.5 \% \mathrm{NaCl} 16 \mathrm{~h}$. For CsrAdependent storage of glycogen analysis, wild-type MG1655 E. coli 
colonies growing on Kornberg medium with $1 \%$ glucose and 100 $\mu \mathrm{g} / \mathrm{mL}$ ampicillin with (pDIA616) and without (pcDNA2.1) csrA were assayed twice for glycogen accumulation. The plates were stained with iodine vapor after $48 \mathrm{~h}$ growth at $25^{\circ} \mathrm{C}$ as in Liu and Romeo (1997). Oxidative stress adaptation was assayed as follows: after overnight growth in TYP medium with $1 \% \mathrm{NaCl}$, bacteria are washed in fresh TYP medium with $1 \% \mathrm{NaCl}$ and diluted to $\mathrm{OD}_{600}=0.15$. When the $\mathrm{OD}_{600}$ reached 0.5 , the culture was separated into four equal parts and then exposed to $0,15,20$, and $25 \mathrm{mM}$ of $\mathrm{H}_{2} \mathrm{O}_{2}$. The $\mathrm{OD}_{600}$ was measured at various times during growth. Experiments were performed twice at $37^{\circ} \mathrm{C}$ for MG1655 E. coli strain and at $15^{\circ} \mathrm{C}$ for $P$. haloplanktis TAC125. For electron microscopy cells were stained with $0.1 \%(\mathrm{v} / \mathrm{v})$ osmium tetroxide prepared in water: $20 \mu \mathrm{L}$ cells were deposited onto 300-mesh copper grids coated with Formvar (Electron Microscopy Sciences). Excess sample was removed by using Whatman 3MM paper. Bacteria were examined at $75 \mathrm{keV}$ under a Hitachi H600 transmission electron microscope. Images' acquisition was performed with a CCD Advantage HR Hamamatsu camera and the AMT 542 software (Advanced Microscopy Techniques).

\section{Genome sequencing, assembly, and annotation}

DNA was isolated from $P$. haloplanktis TAC125 grown in rich medium supplemented with $20 \mathrm{~g} / \mathrm{L} \mathrm{NaCl}$. The complete genome sequence was determined by using the whole shotgun method $(10 \times$ coverage, using two plasmid libraries and one BAC library to order contigs). Finishing was performed by PCR amplification from contigs' extremities. All rDNA clusters were sequenced individually. After a first round of annotation, regions of lower quality as well as regions with putative frameshifts were resequenced from PCR amplification of the dubious regions.

A first set of potential coding sequences (CDSs) was identified by using the AMIGene software (Annotation of MIcrobial Genes) (Bocs et al. 2003) trained with a set of CDSs $>500 \mathrm{bp}$ from the genomic sequence. Three gene models, computed from the three gene classes identified by codon usage analysis (see below), were then subsequently used together in the core of AMIGene with minimum CDSs length set to $60 \mathrm{bp}$. This second set of putative genes (made of 3488 CDSs) was submitted to functional annotation: exhaustive BLAST searches against the UniProt databank were performed to determine significant homology. Protein motifs and domains were documented by using the InterPro databank. In parallel, genes coding for enzymes were classified by using the PRIAM software (Claudel-Renard et al. 2003). PROTMHMM and PRODIV-TMHMM were used to identify transmembrane domains (Viklund and Elofsson 2004), and SignalP 3.0 was used to predict signal peptide regions (Bendtsen et al. 2004). Finally, tRNAs were identified by using tRNAscan-SE (Lowe and Eddy 1997).

Sequence data for comparative analyses were obtained from the National Center for Biotechnology Information (NCBI) databank. Putative orthologs between $P$. haloplanktis and the 228 other genomes were defined as genes showing a minimum of $30 \%$ identity and a ratio of 0.8 of the length of the smallest protein. Orthology relations were strengthened by synteny detection (i.e., conservation of the chromosomal colocalization between pairs of orthologous genes from different genomes) using the Syntonizer software, in which all possible kinds of chromosomal rearrangements are allowed (inversion, insertion/ deletion). A "gap" parameter, representing the maximum number of consecutive genes not involved in a synteny group was set to five genes. Species-specific genes were identified as having no ortholog in the compared species. Specific regions are defined by at least two consecutive specific genes. Insertion of genes with similarities in the compared species was allowed. A gap parameter, representing the maximum number of consecutive genes with similarities, was set to two genes.

All the data (i.e., syntactic and functional annotations, and results of comparative analysis) were stored in a relational database (using the MySQL DBMS software). Each predicted gene was assigned a unique identifier prefixed with "PSHAa" for chrI and "PSHAb" for chrII. Manual validation of the automatic annotation was performed by using the Web interface MaGe (Magnifying Genomes), which allows graphic visualization of the $P$. haloplanktis annotations enhanced by a synchronized representation of synteny groups in other genomes chosen for comparisons. Translation start codons were corrected based on protein homology, proximity of ribosome-binding site, and relative position to predicted signal peptides when present. To this purpose, we used the Artemis sequence Viewer connected to the MaGe system. The $P$. haloplanktis nucleotide sequence and annotation data have been deposited at EMBL databank under accession number CR954246 and CR954247. The PseudoList database is constructed by using the MySQL DBMS, as previously described (Fang et al. 2005).

Correspondence analysis (Benzécri 1984) was used to analyze the data table with the relative synonymous codon usage values of each annotated gene as well as the table of distribution of amino acids in the proteome of $P$. haloplanktis. Clustering into consistent classes used a second method (dynamic clouds) (Delorme and Henaut 1988) that automatically clusters the objects located close to one another.

\section{Acknowledgments}

This work was supported by the European Union Network of Excellence BioSapiens, the French Ministry of Research ACI IMPBio Blastsets and MicroScope, and the Hong Kong Innovation and Technology Commission BIOSUPPORT program. G.M. and M.L.T. thank the Programma Nazionale di Ricerche in Antartide 2004, and grants L.R. 05/03 and CRdC-ATIBB, Regione Campania, Italy. S.D.A. and G.F. acknowledge the support of the Fonds National de la Recherche Scientifique, Belgium.

\section{References}

Barber, C.E., Tang, J.L., Feng, J.X., Pan, M.Q., Wilson, T.J., Slater, H., Dow, J.M., Williams, P., and Daniels, M.J. 1997. A novel regulatory system required for pathogenicity of Xanthomonas campestris is mediated by a small diffusible signal molecule. Mol. Microbiol. 24: $555-566$.

Bartlett, D.H. 1999. Microbial adaptations to the psychrosphere/ piezosphere. J. Mol. Microbiol. Biotechnol. 1: 93-100.

Bendtsen, J.D., Nielsen, H., von Heijne, G., and Brunak, S. 2004. Improved prediction of signal peptides: SignalP 3.0. J. Mol. Biol. 340: $783-795$.

Benzécri, J.P. 1984. L'analyse des données. L'analyse des correspondances. Dunod, Paris.

Bocs, S., Cruveiller, S., Vallenet, D., Nuel, G., and Medigue, C. 2003. AMIGene: Annotation of MIcrobial Genes. Nucleic Acids Res. 31: 3723-3726.

Cilia, V., Lafay, B., and Christen, R. 1996. Sequence heterogeneities among $16 \mathrm{~S}$ ribosomal RNA sequences, and their effect on phylogenetic analyses at the species level. Mol. Biol. Evol. 13: $451-461$.

Claudel-Renard, C., Chevalet, C., Faraut, T., and Kahn, D. 2003. Enzyme-specific profiles for genome annotation: PRIAM. Nucleic Acids Res. 31: 6633-6639.

Claverie, P., Vigano, C., Ruysschaert, J.M., Gerday, C., and Feller, G. 2003. The precursor of a psychrophilic $\alpha$-amylase: Structural characterization and insights into cold adaptation. Biochim. Biophys. Acta 1649: 119-122.

Daniel, R.M., Dines, M., and Petach, H.H. 1996. The denaturation and

\section{Genome Research}

www.genome.org 
degradation of stable enzymes at high temperatures. Biochem. J. 317: $1-11$.

Delorme, M.O. and Henaut, A. 1988. Merging of distance matrices and classification by dynamic clustering. Comput. Appl. Biosci. 4: $453-458$.

del Solar, G., Giraldo, R., Ruiz-Echevarria, M.J., Espinosa, M., and Diaz-Orejas, R. 1998. Replication and control of circular bacterial plasmids. Microbiol. Mol. Biol. Rev. 62: 434-464.

Dersch, P., Kneip, S., and Bremer, E. 1994. The nucleoid-associated DNA-binding protein $\mathrm{H}-\mathrm{NS}$ is required for the efficient adaptation of Escherichia coli K-12 to a cold environment. Mol. Gen. Genet. 245: $255-259$.

Dominguez, D.C. 2004. Calcium signalling in bacteria. Mol. Microbiol. 54: $291-297$.

Duilio, A., Tutino, M.L., and Marino, G. 2004. Recombinant protein production in Antarctic Gram-negative bacteria. Methods Mol. Biol. 267: 225-237.

Enos-Berlage, J.L., Guvener, Z.T., Keenan, C.E., and McCarter, L.L. 2005. Genetic determinants of biofilm development of opaque and translucent Vibrio parahaemolyticus. Mol. Microbiol. 55: 1160-1182.

Fang, G., Ho, C., Qiu, Y., Cubas, V., Yu, Z., Cabau, C., Cheung, F., Moszer, I., and Danchin, A. 2005. Specialized microbial databases for inductive exploration of microbial genome sequences. $B M C$ Genomics 6: 14 .

Felitsky, D.J., Cannon, J.G., Capp, M.W., Hong, J., Van Wynsberghe, A.W., Anderson, C.F., and Record Jr., M.T. 2004. The exclusion of glycine betaine from anionic biopolymer surface: Why glycine betaine is an effective osmoprotectant but also a compatible solute. Biochemistry 43: 14732-14743.

Feller, G. and Gerday, C. 2003. Psychrophilic enzymes: Hot topics in cold adaptation. Nat. Rev. Microbiol. 1: 200-208.

Ferrer, M., Lunsdorf, H., Chernikova, T.N., Yakimov, M., Timmis, K.N., and Golyshin, P.N. 2004. Functional consequences of single:double ring transitions in chaperonins: Life in the cold. Mol. Microbiol. 53: $167-182$.

Georlette, D., Blaise, V., Collins, T., D'Amico, S., Gratia, E., Hoyoux, A., Marx, J.C., Sonan, G., Feller, G., and Gerday, C. 2004. Some like it cold: Biocatalysis at low temperatures. FEMS Microbiol. Rev. 28: $25-42$.

Heidelberg, J.F., Paulsen, I.T., Nelson, K.E., Gaidos, E.J., Nelson, W.C., Read, T.D., Eisen, J.A., Seshadri, R., Ward, N., Methe, B., et al. 2002. Genome sequence of the dissimilatory metal ion-reducing bacterium Shewanella oneidensis. Nat. Biotechnol. 20: 1118-1123.

Hille, R. 2002. Molybdenum and tungsten in biology. Trends Biochem. Sci. 27: 360-367.

Ivanova, E.P., Flavier, S., and Christen, R. 2004. Phylogenetic relationships among marine Alteromonas-like proteobacteria: Emended description of the family Alteromonadaceae and proposal of Pseudoalteromonadaceae fam. nov., Colwelliaceae fam. nov., Shewanellaceae fam. nov., Moritellaceae fam. nov., Ferrimonadaceae fam. nov., Idiomarinaceae fam. nov. and Psychromonadaceae fam. nov. Int. J. Syst. Evol. Microbiol. 54: 1773-1788.

Kierek, K. and Watnick, P.I. 2003. The Vibrio cholerae O139 O-antigen polysaccharide is essential for $\mathrm{Ca}^{2+}$-dependent biofilm development in sea water. Proc. Natl. Acad. Sci. 100: 14357-14362.

Kiley, P.J. and Beinert, H. 2003. The role of Fe-S proteins in sensing and regulation in bacteria. Curr. Opin. Microbiol. 6: 181-185.

Laurent-Winter, C., Ngo, S., Danchin, A., and Bertin, P. 1997. Role of Escherichia coli histone-like nucleoid-structuring protein in bacterial metabolism and stress response: Identification of targets by two-dimensional electrophoresis. Eur. J. Biochem. 244: 767-773.

Lee, S.J. and Gralla, J.D. 2004. Osmo-regulation of bacterial transcription via poised RNA polymerase. Mol. Cell 14: $153-162$

Liu, M.Y. and Romeo, T. 1997. The global regulator CsrA of Escherichio coli is a specific mRNA-binding protein. J. Bacteriol. 179: 4639-4642.

Lobry, J.R. and Louarn, J.M. 2003. Polarisation of prokaryotic chromosomes. Curr. Opin. Microbiol. 6: 101-108.

Lonhienne, T., Gerday, C., and Feller, G. 2000. Psychrophilic enzymes: Revisiting the thermodynamic parameters of activation may explain local flexibility. Biochim. Biophys. Acta 1543: 1-10.

Loschi, L., Brokx, S.J., Hills, T.L., Zhang, G., Bertero, M.G., Lovering, A.L., Weiner, J.H., and Strynadka, N.C. 2004. Structural and biochemical identification of a novel bacterial oxidoreductase. J. Biol. Chem. 279: 50391-50400.

Lowe, T.M. and Eddy, S.R. 1997. tRNAscan-SE: A program for improved detection of transfer RNA genes in genomic sequence. Nucleic Acids
Res. 25: 955-964.

McLean, M.J., Wolfe, K.H., and Devine, K.M. 1998. Base composition skews, replication orientation, and gene orientation in 12 prokaryote genomes. J. Mol. Evol. 47: 691-696.

Meibom, K.L., Li, X.B., Nielsen, A.T., Wu, C.Y., Roseman, S., and Schoolnik, G.K. 2004. The Vibrio cholerae chitin utilization program. Proc. Natl. Acad. Sci. 101: 2524-2529.

Moran, M.A., Buchan, A., Gonzalez, J.M., Heidelberg, J.F., Whitman, W.B., Kiene, R.P., Henriksen, J.R., King, G.M., Belas, R., Fuqua, C., et al. 2004. Genome sequence of Silicibacter pomeroyi reveals adaptations to the marine environment. Nature 432: 910-913.

Nudler, E. and Mironov, A.S. 2004. The riboswitch control of bacterial metabolism. Trends Biochem. Sci. 29: 11-17.

Okada, K., Iida, T., Kita-Tsukamoto, K., and Honda, T. 2005. Vibrios commonly possess two chromosomes. J. Bacteriol. 187: 752-757.

Pascal, G., Médigue, C., and Danchin, A. 2005. Universal biases in protein composition of model prokaryotes. Proteins 60: 27-35.

Rabus, R., Ruepp, A., Frickey, T., Rattei, T., Fartmann, B., Stark, M., Bauer, M., Zibat, A., Lombardot, T., Becker, I., et al. 2004. The genome of Desulfotalea psychrophila, a sulfate-reducing bacterium from permanently cold Arctic sediments. Environ. Microbiol. 6: 887-902.

Raven, J.A., Johnston, A.M., Kubler, J.E., Korb, R., McInroy, S.G., Handley, L.L., Scrimgeour, C.M., Walker, D.I., Beardall, J., Clayton, M.N., et al. 2002. Seaweeds in cold seas: Evolution and carbon acquisition. Ann. Bot. (Lond.) 90: 525-536.

Riemann, L. and Azam, F. 2002. Widespread N-acetyl-D-glucosamine uptake among pelagic marine bacteria and its ecological implications. Appl. Environ. Microbiol. 68: 5554-5562.

Riley, M. 1993. Functions of the gene products of Escherichia coli. Microbiol. Rev. 57: 862-952.

Rocha, E.P. and Danchin, A. 2003. Gene essentiality determines chromosome organisation in bacteria. Nucleic Acids Res. 31: $6570-6577$.

Schneider, B.L., Kiupakis, A.K., and Reitzer, L.J. 1998. Arginine catabolism and the arginine succinyltransferase pathway in Escherichia coli. J. Bacteriol. 180: 4278-4286.

Stratton, L.P., Kelly, R.M., Rowe, J., Shively, J.E., Smith, D.D., Carpenter J.F., and Manning, M.C. 2001. Controlling deamidation rates in a model peptide: Effects of temperature, peptide concentration, and additives. J. Pharm. Sci. 90: 2141-2148.

Tendeng, C. and Bertin, P.N. 2003. H-NS in Gram-negative bacteria: A family of multifaceted proteins. Trends Microbiol. 11: 511-518.

Thomas, D.N. and Dieckmann, G.S. 2002. Antarctic Sea ice: A habitat for extremophiles. Science 295: 641-644.

Timms, A.R. and Bridges, B.A. 1998. Reversion of the tyrosine ochre strain Escherichia coli WU3610 under starvation conditions depends on a new gene tas. Genetics 148: 1627-1635.

Tutino M.L., Duilio, A., Parrilli, E., Remaut, E., Sannia G., and Marino, G. 2001. A novel replication element from an Antarctic plasmid as a tool for the expression of proteins at low temperature. Extremophiles 5: $257-264$.

Ussery, D.W., Binnewies, T.T., Gouveia-Oliveira, R., Jarmer, H., and Hallin, P.F. 2004. Genome update: DNA repeats in bacterial genomes. Microbiology 150: 3519-3521.

Viklund, H. and Elofsson, A. 2004. Best $\alpha$-helical transmembrane protein topology predictions are achieved using hidden Markov models and evolutionary information. Protein Sci. 13: 1908-1917.

Weber, M.H. and Marahiel, M.A. 2003. Bacterial cold shock responses. Sci. Prog. 86: 9-75.

Weintraub, S.J. and Manson, S.R. 2004. Asparagine deamidation: A regulatory hourglass. Mech. Ageing Dev. 125: 255-257.

Zhou, F.X., Cocco, M.J., Russ, W.P., Brunger, A.T., and Engelman, D.M. 2000. Interhelical hydrogen bonding drives strong interactions in membrane proteins. Nat. Struct. Biol. 7: 154-160.

\section{Web site references}

www.genoscope.cns.fr/agc/mage/psychroscope; PsychroScope http://bioinfo.khu.hk/PsychroList; PsychroList

Received May 13, 2005; accepted in revised form August 4, 2005. 


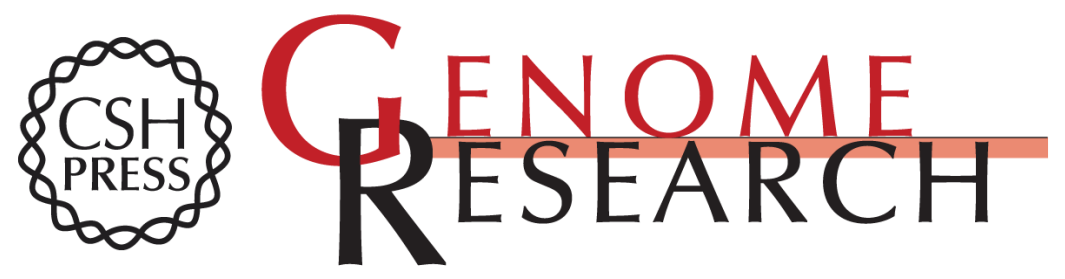

\section{Coping with cold: The genome of the versatile marine Antarctica bacterium Pseudoalteromonas haloplanktis TAC125}

Claudine Médigue, Evelyne Krin, Géraldine Pascal, et al.

Genome Res. 2005 15: 1325-1335

Access the most recent version at doi:10.1101/gr.4126905

Supplemental Material

References License

Email Alerting Service
http://genome.cshlp.org/content/suppl/2005/09/16/gr.4126905.DC1

This article cites 52 articles, 11 of which can be accessed free at: http://genome.cshlp.org/content/15/10/1325.full.html\#ref-list-1

Receive free email alerts when new articles cite this article - sign up in the box at the top right corner of the article or click here.

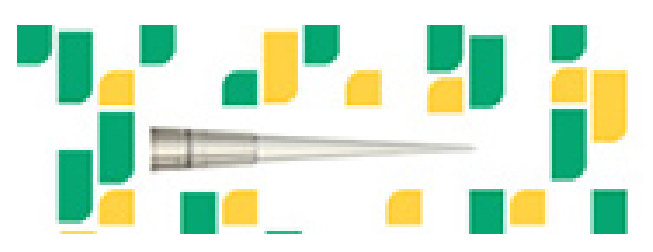

To subscribe to Genome Research go to: https://genome.cshlp.org/subscriptions 